\title{
Fotos que fazem falar: desafios metodológicos para análise de redes temáticas em fotologs*
}

\section{RESUMO}

A predominância de fotologs compondo uma rede temática sobre Síndrome de Down (SD), e sua insignificância numérica em outras redes sobre Pessoas com Necessidades Especiais (PNE) analisadas, faz perguntar: o que se faz melhor em fotologs do que em blogs? O que se faz em blogs que não se torna tão relevante para os pais de crianças com SD? Frente a isso, o objetivo deste artigo é identificar o processo de Inclusão Social (IS) nessa rede, a partir da aplicação de metodologia em duas etapas. Enquanto a netnografia (Hine, 2005, Kozinets, 2002) é utilizada para a identificação, seleção e obtenção de dados dos fotologs selecionados, a Análise de Redes Sociais (ARS) fornece substrato metodológico para a análise das trocas empreendidas na mesma. Assim, buscase entender a foto como motivo de socialização em fotologs e a opção por este tipo de suporte nesta rede temática

\section{PALAVRAS-CHAVE}

socialização on-line

fotologs

redes temáticas

\section{ABSTRACT}

The fact that fotologs predominate on thematic network about Down's syndrom (DS), and the numerical insignificance of this resource on other network about disabled people, raise the question: which advantages do fotologs have over blogs? Which blogs resources are irrelevant for DS children's parents? This article aims to identify the process of social inclusion on this net starting from the application of methodology in two stages. Whereas netnography (Hine, 2005, Kozinets, 2002) is used to identify, select and obtain data of the selected fotologs, the Social Network Analysis (SNA) provides methodological material for analysis of exchanges made on fotologs. Thus, the goal of this paper is to understand the photo as a resource of socialization on fotologs and the option for this kind of support on this thematic network

\section{KEY WORDS}

on-line socialization

photologs

thematic network

\section{Sandra Portella Montardo}

Professora no Centro Universitário Feevale, no Curso de Comunicação Social e no Mestrado em Inclusão Social na Feevale/RS/BR.

sandramontardo@feevale.br

\section{Introdução}

O projeto de pesquisa "Blogs como ferramenta de socialização e inclusão de Pessoas com Necessidades Especiais (PNE)" tem por objetivo verificar como se dá a inclusão social de PNE e de seus familiares em blogs. Em um artigo anterior (Montardo; Passerino, 2007) abordamos vários conceitos de inclusão social (IS) e estabelecemos sua relação com o conceito de inclusão digital (ID). Assim, entendemos que a IS consiste em todas as formas de promover a autonomia de indivíduos que se encontram, temporariamente ou não, e, sob algum aspecto específico, em desvantagem a outros grupos sociais (Azevedo e Barros, 2004; Ladeira e Amaral, 1999; Sposati, 2006). Nesses termos, deve-se ressaltar que a IS é compreendida como um processo permanente, embora não constante, em que todos podem estar, simultaneamente, incluídos em algumas situações e excluídos de outras. A ID, nesse contexto, pode ser vista como uma faceta da IS, ao prover de autonomia os sujeitos que a utilizem para algum fim (Warschauer, 2006).

Tendo-se em vista contemplar o problema de pesquisa "como identificar IS de PNE e de seus familiares em blogs?", mapeamos e analisamos uma rede temática sobre autismo e Síndrome de Asperger em blogs (Montardo; Passerino, 2008) e identificamos três tipos de atuação dos usuários desta rede: os promotores de IS (autores de postagens e de comentários), aqueles que apenas dela usufruem (leitores de comentários), e os que fazem as duas coisas, sob forma de conteúdo informativo ou de apoio emocional. Esses blogs analisados funcionam, assim, como uma extensão de Associação de Pais quanto aos desafios postos pelo autismo e pela Síndrome de Asperger, questões que ainda não estão totalmente definidas no campo científico.

A partir dessa experiência prévia, foi surpreendente constatar que a Síndrome de Down é tema de rede social organizada, mais uma vez por pais de crianças, predominantemente em fotologs. $\mathrm{O}$ primeiro passo para entender o porquê da preferência de fotologs a blogs nesta rede temática foi um levantamento do estado da arte de redes sociais em fotologs, da SD, e uma descrição da aplicação da netnografia como metodologia para obtenção de dados e seleção da amostra desta rede temática em um artigo anterior (Montardo, Goedtel e Etchegaray, 2008). Frente a isso, pretende-se retomar alguns pontoschave levantados nesse estudo para, no seguimento desta investigação, aprofundarmos a compreensão sobre o uso de fotologs por esta rede temática, com a utilização de uma tipologia para fotologs (KUHN Jr., 2008), assim como o estudo do uso da foto em estudos etnográficos 
(Bogdan, 1999, Feldman-Bianco; Moreira Leite, 1998; Galano, 1998) e netnográficos (McDonald, 2007). Com essas abordagens, busca-se complementar o modelo de análise de redes sociais proposto por Recuero (2005) quando aplicado a fotologs, uma vez que se trata aqui de rede temática.

\section{Rede temática: Síndrome de Down}

Uma rede temática pode ser definida como uma rede social na web, portanto como um conjunto de nós e de suas conexões (Recuero, 2005), que se estrutura em torno de um tema específico e que se mantém restrita a ele. Em vários casos, encontra-se redes sociais estabelecidas nos mais diversos suportes (blogs, fotologs, redes sociais, microblogs, etc.) cujos atores se agrupam em nome de alguma afinidade expressa nas mesmas. Contudo, percebe-se, nesses casos, que a afinidade a algum tema é o ponto de partida para as trocas empreendidas, mas não necessariamente o ponto de chegada. Por outras palavras, a afinidade inicial a um tema se desdobra em muitos outros, alguns dos quais acabam por se descolar totalmente do tema inicial. Deve-se destacar que este descolamento definitivamente não acontece nas redes temáticas observadas neste projeto, de modo que seus atores postam textos, fotos, legendas e comentários exclusivamente sobre o tema em torno do qual a rede se estrutura.

A Síndrome de Down (SD) se caracteriza por uma alteração na divisão cromossômica usual, resultando na triplicação do material genético existente no cromossomo 21, ao invés da duplicação deste. (Bissoto, 2005).

Segundo Pereira-Silva e Dessen (2002), ainda que os primeiros registros sobre a SD datem do século XIX, obras de pintores como Andrea Mantegna (1431-1506) e Jacob Jordaens (1539-1678) retratam crianças com a síndrome, já que elas são facilmente reconhecidas por traços específicos nos olhos, orelhas e mãos. De acordo com as autoras (2002), após vários estágios de conhecimento da SD, é apenas em 1866, com Langdon Down, que a SD aparece como uma manifestação clínica, ainda que apoiada em pressupostos evolucionistas, que creditava a deficiência mental a raças inferiores. Após várias denominações para esta síndrome, muitas das quais pejorativas, apenas em 1965 que Organização Mundial da Saúde (OMS) determina a preferência pela expressão Síndrome de Down para designar essa alteração cromossômica.

Como demonstram Martini et. al. (2007), a palavra síndrome designa, em medicina, uma "desordem clínica na qual algumas características ou sintomas comumente ocorrem juntos" (MARTINI et. al., 2007, p. 31). No caso da SD, as características são: "cardiopatia congênita $(40 \%)$; hipotonia (100\%); problemas de audição (50 a $70 \%)$; de visão (15\% a 50\%); alterações na coluna cervical (1 a 10\%); distúrbios da tireóide (15\%); problemas neurológicos (5 a 0\%); obesidade e envelhecimento precoce (MOREIRA et. al., 2000, p. 97), fatores estes que acabam por interferir no desenvolvimento global da criança portadora (Bissoto, 2005).

Em um estudo empírico que interrogou pais de crianças com SD sobre o comunicado deste diagnóstico para a criança, Martini et. al. (2007) concluíram que os pais evitam esse comunicado, em parte, por reviver o desamparo sentido com o comunicado de diagnóstico que receberam do médico no momento do nascimento da criança, o qual enfatiza a deficiência e não as possibilidades desta. Ainda que seja possível identificar a SD antes do nascimento, a maioria dos pais toma conhecimento do fato logo após o parto. Embora as autoras (2007), através de Manoni (1995) e de Jerusalinski (2002), salientem as diferentes formas de respostas desses pais ao fato de terem um filho com SD, é comum que ocorra um sentimento de perda, de luto, com relação ao filho ideal imaginado, sendo que, freqüentemente, entendem o bebê com SD como um impostor que tomou o lugar do filho imaginado.

Isso, por sua vez, pode influenciar de maneira significativa a relação pais-filhos, de acordo com as autoras (2007), principalmente no que tange à falta de expectativas dos pais com relação a esses filhos, o que compromete significativamente o seu desenvolvimento como um todo. Bissoto (2005) questiona uma série de pressupostos teóricos referentes a diagnósticos estáticos da SD, enfatizando a influência dos aspectos sociais, culturais, genéticos e, em decorrência disso, as expectativas que se tem quanto ao desenvolvimento da criança, bem como os aspectos afetivo-emocionais aí implicados. De maneira mais explícita, trata-se de que cada pessoa com SD terá um ritmo de desenvolvimento particular e que, portanto, requer estímulo constante.

De maneira complementar, para que o ambiente familiar proporcione o desenvolvimento pleno da criança SD, é fundamental, como mostra Casarin (1999), citado por Pereira-Silva e Dessen (2002), a reformulação de imagem deformada sobre a SD, por parte desta, que também não seja idealizada e, por isso, que torne viável esse relacionamento favorável ao desenvolvimento.

Esclarecidas algumas questões sobre o tema da rede observada, deve-se saber mais sobre o suporte no qual ela se estabelece.

\section{Fotologs}

"Mistura de blogs com álbuns de fotografia" (RIGONI, 2006), fotologs são páginas pessoais para postagem de fotografias, nas quais as pessoas podem comentar as mesmas (Recuero, 2006). Khalid e Dix (2007) citam Fotolog.com ${ }^{1}$, Fotopages ${ }^{2}$ e o Flickr ${ }^{3}$ indistintamente como sistemas de publicação de fotologs. No entanto, ainda que estes últimos tenham como principal diferença com relação aos álbuns de fotografias apresentar ferramenta de comentários, não dispõem de todos os recursos do Flickr, sistema de compartilhamento de fotos que permite comentários até mesmo dentro das fotos (notes), bem como a sua classificação em tags. 
Por outro lado, a publicação de fotos cuja função ultrapassa a de identificação de perfis, tem conhecido novos suportes, como as redes sociais de relacionamento que, recentemente, têm disponibilizado um número maior de fotos por páginas pessoais, assim como uma ferramenta de comentários para as mesmas.

McDonald (2007) destaca que imagens e compartilhamento de fotos são aspectos importantes e crescentes de comunidades on-line, embora a tradição conhecida em análises de redes sociais privilegia o texto escrito. Em Visual Conversations Styles in Web Communities, o autor (2007) foca a imagem que indivíduos usam para se apresentar e interagir. Na sua interpretação, sites de compartilhamento de fotos são caracterizados por organizar fotos sobre o dia-a-dia de indivíduos, fotoblogs privilegiam um apuro estético maior, como da fotografia tradicional, moblogging é caracterizado pela baixa resolução das fotos tiradas por celular e, finalmente, foto-games são os sites que possibilitam aos usuários que se adicione legendas ou até mesmo a imagem. Para o autor (2007)

"a visual conversation is a collaborative narrative that can be 'read' by an outsider, just like that of a text based conversation. In this 'reading' approach the conversational thread is available for anyone to inspect, given the patience". (McDONALD, 2007, p. 1).

A partir de uma observação casual de centenas de fotologs do portal $\mathrm{Uol}^{4}$, Kuhn Jr.(2008) identifica uma "pulverização temática", passível de ser localizada em mecanismos de busca, nos mesmos, cujas fotos retratam: “1) objetos (carros, armas, brinquedos); 2) natureza (flores, animais de estimação, selvagens, insetos); 3)pessoas (indivíduos, auto-retratos, familiares, amigos reunidos, festas familiares, coletividades, crianças, colegas de escola); 4) lugares (espaços domésticos, escola, cidades, ruas, cenas urbanas, natureza e paisagens) e estruturas, arquitetura (edifícios, monumentos); 5) conceitos fotográficos (texturas, abstratos, "macros", movimento/estática); 6) acontecimentos e personagens do mundo midiático (eventos, concertos, shows, notícias/jornalismo, artistas, músicos); 7) desenho, arte, poesia visual e 8) aventura, viagens, expedições." (KUHN Jr., 2008, p. 105106).

A partir dessa variedade temática, Kuhn Jr. (2008) propõe uma tipologia para os usos do fotográfico em fotologs como dinamizador de interações na internet. Segundo o autor (2008) esses usos do fotográfico podem ser classificados da seguinte forma: 1) compartilhamento de experiências (molduras de documentação e memória cotidiana; molduras de documentação e memória de deslocamentos espaciais; molduras de experimentação narcísea), 2) partilhamento de qualidade dos conteúdos (colagens fotográficas e colecionismos temáticos; efeito publicidade; iconografia midiática) e, finalmente, 3) compartilhamento do ato fotográfico em si (pictorialismo infográfico; pictorialismo fotográfico).

$\mathrm{Na}$ amostra observada neste estudo, identifica-se o uso do compartilhamento de experiências, sob forma de molduras de documentação e memória cotidiana, bem como de moldura de documentação e memória de deslocamentos espaciais. No primeiro caso, o conteúdo fotografado está implicado no gesto fotográfico, devido ao "conteúdo vivencial se revelar significativamente na própria condição da experiência fotograficamente vivida" (KUHN Jr., 2008, p. 109), constituindo painéis de fotos sobre situações como nascimentos de um bebê, festas de aniversário, reuniões entre amigos, em que a vivência retratada se sobressai à qualidade fotográfica do conteúdo em si, bem como de sua autoria. Da mesma forma, o segundo caso privilegia a situação vivida pelo fotógrafo-fotografado, e a experiência vivida toma forma de painéis fotográficos de diários de viagem.

O item que segue, faz referência ao processo de observação e coleta de dados em redes de fotologs para que, então, observe-se padrões de usos do fotográfico por esta rede temática e de que forma a conversação se estabelece em relação às fotos.

\section{Aplicação da netnografia em rede temática de fotologs}

Goetz e Lecompte (1988) afirmam que uma etnografia é uma reconstrução analítica de cenários e grupos culturais que contempla as crenças, práticas, artefatos e conhecimentos compartilhados pela cultura que está sendo estudada, através de uma imersão profunda do pesquisado no grupo estudado. Já Batzán (1995) destaca o aspecto descritivo do estudo etnográfico, visando a compreensão global da cultura em questão. Para Hine (2005), etnografia é uma sistematização em dados da experiência de observações face-a-face, visando captar uma "performance de comunidade". Ainda Goetz e Lecompte (1988) apontam que não somente a re-criação do cenário é importante como resultado de pesquisa, mas o também o próprio método utilizado.

Segundo Hine (2005) a internet se oferece ao mesmo tempo como contexto cultural e artefato cultural, justificando a aplicação da etnografia virtual em grupos que ali se estabelecem. Na mesma direção, Schneider e Foot (2005) entendem a internet como cenário técnico que suporta a ação on-line com implicações sociais, políticas e econômicas.

Kozinets (2002) propõe uma adaptação da etnografia para a netnografia, indicando as ressalvas e as oportunidades que devem ser observadas em função de se estar analisando grupos na web, predominantemente à distância. Na medida em que o uso da netnografia no estudo de blogs (Montardo, Passerino, 2006) e combinada à Análise de Redes Sociais (ARS) (Montardo, Passerino, 2008) estão relatados em estudos anteriores, passaremos direto à descrição do processo, baseado nestas etapas.

Importa ressaltar que a netnografia é requerida em um primeiro momento da pesquisa, durante os processos de seleção de amostra e de obtenção de dados sobre a rede temática em questão. Quanto a isso, o levantamento dos 
blogs sobre SD começou pelo site Pesquisa de Blogs Google $^{5}$ e com a ferramenta de busca do site Technorati ${ }^{6}$, em busca de palavras-chave e expressões como "Síndrome de Down", "tenho Síndrome de Down", "sou mãe de SD", etc. Em um segundo momento, a partir de blogs e fotologs encontrados, identificou-se a ocorrência de nosso objeto de busca em blogrolls e em fotologs favoritos.

Em seguida, por meio de comentário nos próprios blogs e fotologs encontrados, explicamos brevemente o objetivo da pesquisa, deixamos um endereço de e-mail para contato e, também, um link para o blog da pesquisa (Blogs Especiais) ${ }^{7}$, que traz o vínculo dos pesquisadores com a Instituição em que se desenvolve o projeto, bem como links para os Currículos Lattes de todas a equipe ligada a ele. Nesse comentário, solicitamos a autorização para observar os blogs e fotologs sobre SD levantados, que deveria ser dada por e-mail, endereçado à líder do projeto. Esse processo foi realizado do início de março até o dia 10 de abril de 2008.

Entre os 44 blogs e fotologs encontrados, de autoria de pais, amigos e dos próprios SD, recebemos autorização de 12 pais de crianças com SD, todos autores de fotologs. Havia, entretanto, outros 25 fotologs que não retornaram o e-mail. Respondemos os e-mails com a autorização, enviando em anexo um Termo de Compromisso para Uso de Dados, comprometendo-nos a utilizarmos os dados somente para fins de pesquisa, sem identificarmos os fotologs.

Com relações a questões éticas semelhantes, $\mathrm{McDo-}$ nald (2007) salienta que comunicou os administradores de sites cujas fotos seriam utilizadas em publicações, obtendo permissão para utilizar determinadas fotos específicas. Além disso, o autor (2007) informa que se esforçou para contatar as pessoas que aparecem nas fotos, sendo que as fotos de quem o pesquisador não obteve resposta foram manipuladas para evitar a sua identificação. Nesse caso, a análise da rede pelo autor (2007) foi feita antes de se obter permissão para utilização das imagens, estando apenas a comunicação dos resultados de pesquisa condicionada, em parte, a essa solicitação.

A coleta de conteúdo destes fotologs se deu pela transcrição da URL dos fotologs, da URL de cada um dos álbuns e de suas respectivas fotos, assim como das legendas destas e dos comentários recebidos em tabelas. $\mathrm{O}$ objetivo é que se pudesse, a partir dessa sistematização, estabelecer padrões de socialização na rede considera$\mathrm{da}^{8}$ e, assim, verificar como se dá o processo de inclusão social na mesma, após o seu mapeamento, que será mostrado a seguir.

Em comparação à aplicação de netnografia em blogs, essa técnica de pesquisa aplicada em fotologs exigiu adaptações quanto à organização de tabelas, que passou a comportar a divisão entre álbuns e as fotografias postadas em cada um deles, bem como questões e categorizações relacionadas à imagem e si.

Quanto ao desafio do uso da imagem em pesquisas em ciências sociais, tem-se que "em diversos casos, o texto escrito e o visual aparecem juntos, e se complementam. Mas existem aqueles em que o divórcio entre os dois é completo. A leitura atenta pode isolá-los, ignorando um e levando em conta apenas o outro" (Moreira Leite, 1998, p. 38). No entanto, no que se relaciona à análise de fotologs, na maior parte dos casos, tem-se legendas, se não de todas as fotos, do álbum, o que vincula um sentido de observação de quem posta a foto para quem a acessa. Acredita-se que ambos os direcionamentos devem ser levados em conta por parte do pesquisador, principalmente se os usos do fotográfico privilegiarem o compartilhamento de experiências (memória cotidiana ou deslocamentos espaciais), segundo Kuhn Jr. (20008) e não a qualidade do fotográfico em si.

Bogdan (1999) afirma que fotografias podem ser utilizadas em pesquisas para entender como as pessoas sobre as quais se investiga definem o seu mundo. Galano (1998) entende que as fotos podem ser utilizadas tanto para fotografar objetos de pesquisa quanto para gerar conversação acerca deles. Neste último caso, o ato de fotografar é mais importante do que as fotos em si, porque faz falar a respeito do que se fotografa.

Pode-se dizer que não só as legendas das fotos, mas também o registro presente das datas de postagem e de comentários facilitam a ordenação do sentido e delimitam um tempo de observação para legibilidade visual adequada requerida do pesquisador, de acordo com Moreira Leite (1998). A autora ainda acrescenta, relativamente à pertinência do uso da foto como fonte de pesquisa:

O estudo da prática fotográfica e da significação da imagem produzida revela regularidades objetivas de comportamento coletivo e experiência vivida desses comportamentos. Exige, contudo, um exercício perseverante e resistente à fadiga visual, acrescido por observação e imaginação, alimentadas por um julgamento capaz de orientar deduções e comparações contínuas (Moreira Leite, 1998, p. 41).

Uma forma de facilitarmos a análise dos materiais coletados foi a organização do conteúdo em tabelas. Foi feita uma tabela para cada fotolog, em cujo cabeçalho constavam nome do fotolog, autor, URL, data da primeira publicação e número de álbuns e de fotos em cada um deles no período observado (dezembro de 2007 a março de 2008). Abaixo do cabeçalho, foi reservado um campo para anotações gerais sobre este blog. As tabelas em si foram organizadas da seguinte forma:

Percebe-se, na organização das tabelas, a preocupação em permitir a sistematização dos dados obtidos em termos de Análise de Redes Sociais, etapa posterior, o que demandou algumas adaptações em relação à análise de blogs, elaborada exclusivamente em torno de texto verbal. Ball e Smith (1992) e Pink (2001), citados por McDonald (2007), destacam que a análise de texto é 
Fotos que fazem falar: desafios metodológicos para análises de redes temática em fotologs • 75 - 84

Tabela 1: Organização dos dados obtidos em rede temática sobre Síndrome de Down em Fotologs

\begin{tabular}{|c|c|c|c|c|c|}
\hline $\begin{array}{l}\text { URL do álbum e } \\
\text { de cada foto, } \\
\text { acompanhada da } \\
\text { transcrição da } \\
\text { legenda e da } \\
\text { data/hora de sua } \\
\text { publicação. }\end{array}$ & $\begin{array}{l}\text { Sobre a foto } \\
\text { 1) Onde a foto foi tirada? } \\
\text { 2) Como foi tirada (posada } \\
\text { ou espontânea)? } \\
\text { 3) Quem aparece na foto? } \\
\text { 4) Quem tirou a foto? } \\
\text { 5) Em que contexto é } \\
\text { mostrada a SD? }\end{array}$ & $\begin{array}{l}\text { Tipo de uso do } \\
\text { fotográfico } \\
\text { (Kuhn Jr., 2008) }\end{array}$ & $\begin{array}{l}\text { Comentários (autor, } \\
\text { e-mail e/ou URL do } \\
\text { autor, transcrição do } \\
\text { comentário, data/hora } \\
\text { de sua publicação. }\end{array}$ & $\begin{array}{c}\text { Capital } \\
\text { Social }\end{array}$ & $\begin{array}{l}\text { Laços } \\
\text { Sociais }\end{array}$ \\
\hline
\end{tabular}

vantajosa sobre a imagem porque: 1) é mais fácil coletar, processar e manipular textos do que imagens; 2) o texto é mais simples de ser anonimizado; e 3) aplicação de métodos analíticos em textos são mais recorrentes. $\mathrm{O}$ autor (2007) ainda acrescenta que existem inúmeras ferramentas computacionais (mineração de dados) para analisar extensos corpus de textos, enquanto que com a imagem isso ainda não acontece.

Nesse sentido, cabe fornecer condições para que, na análise, possa-se estabelecer a relação entre o suporte em que esta rede se estabelece (fotologs) e de suas possíveis implicações com o tema em questão (SD).

\section{Análise de Redes Sociais em rede de fotologs sobre Síndrome de Down e discussão de resultados}

O mapeamento visual dessa rede, identificando-se quais fotologs estão ligados a quais outros, quem comenta no fotolog de quem, fotos de qual tipo são mostradas nesses suportes, que tipo de comentários são feitos, é o que viabiliza a análise desta rede, paralelamente à análise dos conteúdos das tabelas. O mapeamento da rede temática obtida, foi elaborada com o software CMap Tools ${ }^{9}$.

Da mesma forma, foram feitos dois mapas para cada fotolog da rede: um para mostrar os links deste fotolog para os demais desta rede, e outro contendo os comentários para o fotolog em questão no período considerado, com diferenciação de cores para os comentários feitos por autores de fotologs desta rede.

$\mathrm{Na}$ busca de um modelo de análise de redes sociais que contemple o aspecto qualitativo das interações, utilizaremos mais uma vez o proposto por Recuero (2005) que é constituído de três elementos principais: organização, estrutura e dinâmica. Enquanto a organização se relaciona à interação social em um grupo, a estrutura se refere ao resultado das trocas empreendidas em um grupo, em termos de laços sociais e de capital social. Finalmente, a dinâmica trata das modificações sofridas por uma rede com o passar do tempo. Conforme já se pode perceber na tabela para sistematização de análise dos conteúdos, organização e estrutura da rede serão privilegiadas, uma vez que a dinâmica de redes temáticas sobre PNE tende a ser exclusivamente de cooperação. Para a análise da estrutura, pretendendo-se a visualização dessas redes e os tipos de conexão que as formam, porém, vamos aplicar a adaptação sugerida a este modelo em um estudo anterior (Montardo; Paserino, 2008), que deduz o tipo de laço social, conforme Granovetter (forte ou fraco) a partir da análise em conjunto do capital social $^{10}$ implícito na postagem, de acordo com Bertolini e Bravo (2004), e de sua correspondência ou não nos comentários. Por exemplo, se o conteúdo da postagem (ou nesse caso, da legenda dos álbuns e das fotos) contiver um caráter relacional e, em resposta, um comentário for feito correspondendo a essa expectativa, sob forma de um comentário de caráter relacional, tem-se um laço forte. Caso contrário, caso uma legenda de foto privilegie um aspecto cognitivo e obtiver como resposta um apelo emocional, configura-se um laço fraco.

Um primeiro aspecto que chamou atenção foi o fato de que todos os fotologs que autorizaram a observação pertencem ao mesmo sistema de publicação (NaFoto.net), ligado ao portal Uol. De acordo com as respostas às Perguntas Freqüentes relacionadas ao UOL Fotoblog ${ }^{11}$, a única diferença entre este sistema de publicação e o NaFoto.net é que, no último caso, visitantes cadastrados poderão utilizar endereços livres (que não sejam do Uol) para se logar, não tendo, necessariamente, nada a ver com os endereços eletrônicos NaFoto.Net. Já assinantes Uol devem utilizar seu endereço Uol para se cadastrarem ao Uol Fotoblog e podem, simultaneamente, utilizar endereços livres no NaFoto.net. Fica claro, com isso, que o Nafoto.net é uma estratégia do provedor Uol de manter sistemas de publicação para atender, também, quem não é seu assinante.

Posteriormente, a análise $\mathrm{e}^{12}$, principalmente dos comentários dos fotologs da amostra, trouxe referências repetidas "à família Happy Down" que, verificou-se depois, funciona e percebe-se como um verdadeiro portal de fotologs sobre Síndrome de Down ${ }^{13}$, publicado no Nafoto.net. Na descrição do Happy Down, em "Sobre nós", consta a seguinte definição: "Somos um grupo de familiares de pessoas com Síndrome de Down e formamos uma grande família.Uma família alegre, solidária e sempre pronta a participar"14.

Em termos gerais, nota-se que o motivo para socialização da rede é constante, no sentido de que foi em função de se ter um filho (a) com SD é que os pais/mães decidiram publicar um fotolog e linká-lo ao fotolog Happy 
Figura 2: Mapa da rede temática sobre Síndrome de Down em fotologs

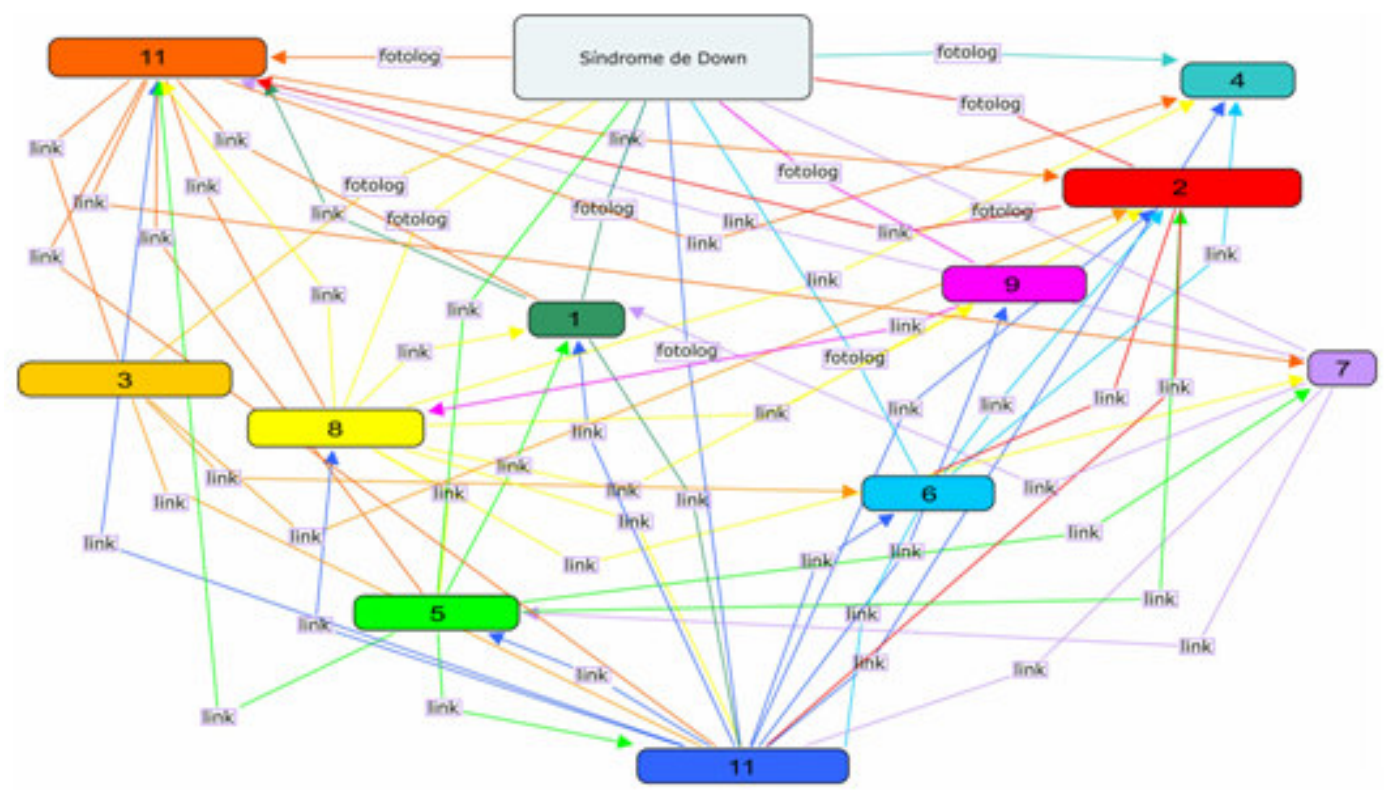

Down. Com exceção de um fotolog, em que o pai e a mãe da criança SD postam as fotos e as legendas (e até comentários), os demais fotologs são mantidos por mães, cujos textos das legendas de fotos são escritos em primeira pessoa, como se fosse a criança, em muitos casos, bebês, que o tivessem escrito. Em uma legenda de fotolog da rede, lê-se, por exemplo: “Este ano vamos aprender a falar e desenhar. Vamos melhorar nosso jeito de montar". Por conseqüência, a maioria dos comentários direciona-se às crianças retratadas, como se observa: "então não esquece de passar por aqui e pegar a titia Lilian ${ }^{15}$ para irmos para o Litoral hein!!bjs estamos contando nos dedinhos para te ver beijão".

Da mesma forma, na identificação de autoria dos comentários, são raros os casos de pessoas que não se definem como mães (Ex. fictício: Maria, mãe do Luciano) e, na maioria dos casos, mães de crianças com SD, como se presume a partir dos textos e seguindo os links de fotologs.

As duas citações a seguir, copiadas, respectivamente, de uma legenda e em um comentário em fotologs da amostra, evidenciam vários pontos importantes para a análise:

Somos um grupo de pais, familiares e amigos de pessoas com Síndrome de Down, e desde antes do Júnior ${ }^{16}$ nascer (quando ele ainda estava na minha barriga) já fazíamos parte deste grupo (Happy Down), assim como o grupo Síndrome de Down. Ambos são grupos da internet, onde recebemos e trocamos e-mails todos os dias a respeito de variados assuntos sobre nossos filhos. Os fotoblogs ajudam muito a nos conhecermos e nos identificarmos quando nos encontramos nas festas de confraternização.
Oi amei seu blog, lindas fotos e o fundo então...como fez???Já cliquei e tentei colocar no do meu filhinho, vc pode me ajudar? Marisa ${ }^{17}$ mãe do Márcio ${ }^{18} 27$ semanas de gestação da família Happydown

Nas duas citações anteriores, as mães revelam que souberam do diagnóstico de seus filhos antes do parto e que buscaram apoio de redes formadas na web sobre a SD. A primeira citação mostra que essas redes se acomodam em mais de um suporte, cujas funções de socialização são diferentes. Assim, cabe ao e-mail ser portador de informações e apoio sobre temas variados, provavelmente, de maneira mais específica, ligados à $\mathrm{SD}$ e, ao fotolog, identificar visualmente as pessoas que compõem essa rede, o que aponta para outro aspecto relevante: os encontros presenciais. Já a segunda citação faz referência à personalização dos fotologs e a intenção de uma mãe de criar o fotolog do seu filho antes mesmo de seu nascimento. Alguns fotologs, ainda que tenham sido elaborados no mesmo sistema de publicação, trazem animações, sons, demonstrando uma certa sofisticação em sua elaboração.

Os encontros presenciais, já evidenciados anteriormente, seja em legendas ou em fotos, são uma constante nesta rede. Estes encontros acontecem tanto sob forma de visita de uma família à outra, às vezes em cidades diferentes, quanto movidos por uma motivação institucional (fim de semana em colônia de férias de famílias com crianças que tenham alguma necessidade especial). Exemplo de comentário de duas mães que só se conheciam pelo fotolog, no período observado, em que um delas está no exterior: "Júlia ${ }^{19}$ o seu convite ja ta aceito viu rsss, quando voltarmos, queremos sim visitar voces e conhece-los pessoalmente! Lucas ${ }^{20}$ se cuida viu porque 
vou te abraçar e te beijar muiiiiiiitooooooo!!!Beijos com carinho".

Nesta rede, o tipo de capital social predominante é o relacional e que os laços sociais são fortes. No entanto, em comparação à rede sobre Autismo e Síndrome de Asperger, aparece com força o tipo de capital confiança no ambiente social, que não se destacou naquela rede temática. Outro ponto importante, nesta comparação, é que na rede sobre SD em fotologs, os temas recorrentes nas fotos são festas de aniversário, férias, escolinha, encontros familiares e situações do cotidiano em que aparece algum tipo de superação no desenvolvimento das crianças (aprender a andar antes do previsto, por exemplo). Os comentários recebidos são feitos por um círculo reduzido de pessoas, que na maioria das vezes é familiar da autora do fotolog ou que conhece pessoalmente a família. Não raro, as pessoas também aparecem nas próprias fotos que comentam.

Pouco se menciona, em texto verbal, sobre a SD em si. Portanto, a SD aparece nesta rede quase que exclusivamente sob forma de fotos das crianças. Algumas exceções estão representadas a seguir, em uma legenda de foto e em comentário feito a essa foto, respectivamente:

Juliano $^{21}$ e a mamãe na Capa da Revista $X^{22}$ Juliano meu amor, nunca imaginei que vc tivésse uma oportunidade tão linda, sair na revista do nosso bairro e mostrar como é lindo o seu sorriso e que crianças especiais como você são mais que especiais são extraordinárias.

Puxa Sônia ${ }^{23} \mathrm{q}$ legal, isso foi muito bom para q a sociedade perceba q um rostinho diferente ñ impede de ser gente igual a qualquer outro ser humano, preciso fazer isso, mostrar nosso filhos, fazer com q eles se incluam na sociedade sem diferença, seu filho é lindo e vcs estão de parabéns. Valeu a pena passar por aqui para conheçer vcs, beijos mamãe Lilian $^{24}$. Conheça também a Pâmela ${ }^{25}$, vc vai amá-la.

Outro comentário retoma esse ponto:

Passeando pelos blog encontrei o seu, parei aqui para lhe dizer que achei a Maria ${ }^{26}$ muito bonita e carismática. Também queria lhe dizer que nunca deixe de acreditar que ela pode tudo e que para Deus nada é impossivel. Tenho uma filha, seu nome é Joana ${ }^{27}$ ela é down. Em 2003 ela casou-se com o João ${ }^{28}$, tb down. Se quiser ver as fotos de casamento elas estão no meu site $[. . .]^{29}$. Lembre-se para Deus nada é impossivel. bjs Lúcia ${ }^{30}$

Nesse caso, percebe-se uma intenção de aconselhamento da mãe de uma pessoa com SD adulta e que também utiliza as fotografias na web, em álbum de fotos, para celebrar, registrar e divulgar a vida de sua filha, em relação à criança de outra mãe, que sugere algumas angústias em relação ao seu futuro.

Ainda em termos da comparação anterior, é válido ressaltar que o ritmo de postagem e de comentários em blogs e em fotologs é bem diferente. Enquanto os primeiros exigem uma certa reflexão e elaboração textual mais densa, a foto exige apenas uma legenda, que, costuma ser breve e descreve apenas o conteúdo da foto. O resultado disso são álbuns com muitas fotos e, nem sempre, com comentários relativos a ela. Deve-se registrar, porém, a existência de legendas que podem ser vistas como verdadeiras postagens, dado à sua extensão e densidade.

Por outro lado, Autismo e Síndrome de Asperger são mais difíceis de serem diagnosticados, porque são temas que ainda não estão totalmente dominados do ponto de vista científico, o que rende muitas elocubrações, dúvidas e discussões por parte das pessoas interessadas. Por outro lado, trata-se, nos dois casos, de necessidades especiais que não podem ser identificadas por imagens. Esses dois pontos tomados em conjunto tornam a rede mais pertinente ao texto verbal dos blogs do que em fotologs.

Já a SD pode ser diagnosticada antes mesmo do nascimento da criança, já é amplamente reconhecida pela comunidade científica desde o século XIX e pode ser identificada visualmente. Por outras palavras, talvez pelo fato de se ter o que mostrar sobre ela, e que e-mails em listas de discussão são utilizados para trocas mais cognitivas, digamos assim, é que esta rede tenha se organizado em fotologs. Entretanto, nossa análise aponta mais um aspecto quanto a isso.

Conforme foi posto, há evidência de capital confiança no ambiente social nessa rede. Credita-se isso ao fato de que todos os fotologs analisados façam parte da "família Happy Down", o que confere um sentimento de pertencimento à rede temática. Nesse contexto, não apenas a noção de laços sociais fortes e fracos, segundo Granovetter $(1973,1983)$, problematizado em um artigo anterior, deve ser referenciado. Aqui, é válido, também, evocarmos Breiger (1974), citado por Recuero (2005), uma vez que se tem um caso em que os laços relacionais (voluntários) e os associativos (pertencimento) se sobrepõem. Assim, as fotos praticamente dispensam a forma verbal de expressão quanto à SD, em legendas e em comentários, embora essa ocorrência esteja combinada com a sedimentação dos laços exercida pelo portal Happy Down sobre a rede considerada.

\section{Considerações finais}

Frente ao que foi visto, deve-se observar que a Netnografia e Análise de Redes Sociais (ARS) são metodologias complementares nesta pesquisa. Enquanto a primeira oferece a sistematização para o acesso do conteúdo a ser analisado, a segunda viabiliza uma observação sobre o tipo de troca que se estabelece na rede, a fim de que se 
verifique de que forma se dá a Inclusão Social na rede considerada.

Com relação à rede temática, dois pontos devem ser levados em conta de forma complementar: o tema que rege a rede em questão e o suporte em que ela se desenvolve. Como foi posto, por um lado, a SD tem um histórico de registro pictórico, na medida em que se trata de uma síndrome com consequiências fenotípicas, captáveis, portanto, em nível imagético, de modo que seu aparecimento nas artes antecede seu registro na ciência. O estabelecimento desta rede em particular se deu em fotologs, ferramenta que possibilita a postagem de fotos (álbuns) e a interação entre os grupos por meio dos comentários, constituindo uma rede social (Recuero, 2008). Diante dessa evidência, coube buscar entender por quais motivos, através da padronização dos usos da ferramenta por essa rede temática.

A análise das fotos, em conjunto com as legendas e comentários, revela que o compartilhamento

de experiências, seja sob a forma de registro de memória cotidiana ou de deslocamentos espaciais, é o principal uso do fotográfico observado, dentre os propostos por Kuhn Jr. (2008). O capital social predominante é o relacional, que, nesta rede, vem acompanhado de uma forte carga de confiança no ambiente social, provavelmente devido ao fato de que todos os fotologs analisados estão linkados ao portal de fotologs sobre SD, Happy Down. Tal qual estudo sobre interações sociais em fotologs (Recuero, 2008), percebe-se claramente a predominância do uso dos comentários como forma de manutenção de laços pré-existentes, muitos dos quais originados na própria comunidade de fotologs. Indicativo disso são as fotos, legendas e comentários registrando os encontros presenciais dos fotologueiros desta rede ou intenção de contatos on-line sobre o mesmo tema em outros suportes (MSN, e-mail, etc). Além disso, deve-se destacar a sobreposição de laços relacionais e associativos nesta rede, segundo Breiger (1974).

Frente a isso, interpreta-se que a socialização on-line em fotologs em uma rede temática sobre SD demonstra, em primeiro lugar, a aceitação dos pais em relação ao diagnóstico de SD dos seus filhos. Esse ponto sugere a superação, pelo menos de quem participa de redes temáticas sobre SD, de uma postura observada antigamente de se "esconder" crianças com SD, cujo diagnóstico pode ser revelado apenas com o olhar sobre elas. Ao contrário, é interessante perceber que o suporte escolhido para esta rede temática foi justamente o que, por definição, explicita e disponibiliza a imagem de seus filhos e que encoraja outros pais a fazê-lo. Além disso, esses fotologs poderão servir, também, como um instrumento auxiliar para compreensão da própria criança quanto ao seu diagnóstico, estimulando o seu autoconhecimento e, conseqüentemente, o seu desenvolvimento. Pode-se dizer, com isso, que na rede temática sobre SD em fotologs, os pais tanto promovem quanto usufruem da Inclusão Social, ao manterem e comentarem em fotologs. Da mesma forma, os fotologs poderão servir como um registro do desenvolvimento das crianças SD, o que vai favorecer a sua própria inclusão maMecos

\section{NOTAS}

* Texto apresentado na ABCiber.

1. Disponível em http:/ / www.fotologs.com.

2. Disponível em http://www.fotopages.com.

3. Disponível em http://www.flickr.com

4. Disponível em http:/ / fotoblog.uol.com.br

5. Disponível em http://www.google.com.br.

6. Disponível em http://www.technorati.com.

7. Disponívelemhttp://www.blogsespeciais.blogspot.com

8. Sobre Análise de Redes Sociais aplicada a este projeto, ver Montardo e Passerino (2008).

9. “O CMapTools um software destinado à elaboração de mapas conceituais. Criados pelo psicólogo americano Joseph Novak e baseados na teoria da aprendizagem significativa de David Ausubel. Estes mapas são diagramas bidimensionais com a finalidade de representar conceitos e suas respectivas proposições". (BENKENSTEIN, MONTARDO, PASSERINO, 2007, p. 7). O mapeamento foi realizado por Maite Etchegaray (BIC-CNPq) e por Elias Ferreira Goedtel (BIC-Fapergs) no primeiro semestre deste ano.

10. Para Bertolini e Bravo (2004), citados por Recuero (2005), existem cinco tipos de capital social: relacional, normativo, cognitivo, confiança no ambiente social e institucional.

11. Disponível em http://fotoblog.uol.com.br/stc/ faq_geral.html.

12. Os fotologs da amostra também foram analisados por Liliana Maria Passerino (PPGIE-UFRGS), colaboradora deste projeto de pesquisa.

13. Disponível em http:/ / happydown.nafoto.net.

14. Disponível em http:/ / happydown.nafoto.net.

15. Nome fictício.

16. Nome fictício.

17. Nome fictício.

18. Nome fictício. 
19. Nome fictício.

20. Nome fictício.

21. Nome fictício.

22. Nome fictício.

23. Nome fictício.

24. Nome fictício.

25. Nome fictício.

26. Nome fictício.

27. Nome fictício.

28. Nome fictício.

29. URL suprimida.

30. Nome fictício.

\section{REFERÊNCIAS}

AZEVEDO, P. H.; BARROS, J. F. O nível de participação do Estado na gestão do esporte brasileiro como fator de inclusão social de pessoas portadoras de deficiência. Revista Brasileira de Ci e Movimento. Brasília, v. 12 n. 1 p. 77-84. Jan/Mar 2004.

BAZTÁN, A. Etnografía. Metodologia cualitativa em la investigación sociocultural. Barcelona: Boixareu Universitária, 1995.

BENKENSTEIN, Arnoldo MONTARDO, S. P.; PASSERINO, Liliana. Análise das Redes Sociais em Blogs de Pessoas com Necessidades Especiais (PNE). In: Revista Novas Tecnologias na Educação (RENOTE). Porto Alegre: UFRGS, Vol. 5, no. 2, Dez. 2007. Disponível em: <http:/ / www.cinted.ufrgs.br/renote/dez2007/ artigos/6hLilianaPasserino.pdf $>$. Acesso em 5 de out. 2008 .

BERTOLINI, S.; BRAVO, G. Social Capital, a Multidimensional Concept.Disponível em <http:// www.ex.ac.uk/shipss/politics/research/socialcapital/other/bertolini.pdf>. Acesso em 10 out. 2008.

BISSOTO, M. L. Desenvolvimento cognitivo e o processo de aprendizagem do portador de Síndrome de Down: revendo concepções e perspectivas educacionais. In: Revista Ciências e Cognição, 2005, Vol. 4, pp. 80-88.

BOGDAN, R. Investigação qualitativa em educação: uma introdução à teoria e aos métodos. Lisboa: Porto, 1999.
BREIGER, R. The Duality of Persons and Groups. Social Forces, vol 53, n. 2, p.181-190, dez. 1974.

FELDMAN-BIANCO, B.; MOREIRA LEITE, M. Desafios da imagem. Fotografia, iconografia e vídeo nas ciências sociais. Campinas, SP: Papirus, 1998.

GALANO, A. M. Iniciação à pesquisa com imagens. In: FELDMAN-BIANCO, B.; MOREIRA LEITE, M. Desafios da imagem. Fotografia, iconografia e vídeo nas ciências sociais. Campinas, SP: Papirus, 1998.

GOETZ, J. P. e LECOMPTE, M. Etnografia y Diseño Cualitativo en InvestigaciónEducativa. Madri: Morata, 1988.

GRANOVETTER, M. The strenght of weak ties: a network theory revisited. In: Sociological Theory, Volume 1. 1983, p.201-233.

. The strenght of weak ties. In: American Journal of Sociology, 78, p. 1360-1380, 1973.

Happy Down. Disponível em <http:// happydown.nafoto.net>. Acesso em 10 out. 2008.

HINE, C. (Ed.). VirtualMethods.Issuesin Social Research on the Internet. Oxford: Berg, 2005.

The field behind the screen. Using Netnography for marketing research in online communities, 2002. Disponível em:http://www.marketingpower.com/ content18255.php. Acesso em 9 out. 2008.

LADEIRA, F.; AMARAL, I. A educação de alunos com multideficiência nas Escolas de Ensino Regular. Coleção Apoios Educativos. Lisboa: Ministério da Educação.Departamento da Educação Básica, 1999.

KHALID, H.; DIX, A. (2007). I know what you did in last Summer. What can we learn from photoblog? Disponível em <http://sunschlichter0.informatik.tumuenchen.de/persons/kochm/ecscw2007ws/paper-khalid.pdf>. Acesso em 5 out. 2008.

KHUN Jr., N. Painéis Fotográficos na Internet. Um estudo dos Fotologs como molduras de mostração. Tese de Doutorado. Programa de Pós-Graduação em Ciências da Comunicação. Universidade do Vale do Rio do Sinos. São Leopoldo, 2008.

MARTINI, F. de O.; LIPP, L.K.; SANTOS, T. F. ; OLIVEIRA-MENEGOTTO, L. M. Você tem Síndrome de Down: algumas reflexões sobre a não-comunicação do diagnóstico entre pais e filhos. In: Revista Prâksis. Novo Hamburgo, Ano 4, V. 2, Ago. 2007, pp. 31-37. Disponível em <http:/ / www.feevale.br/internas/ 
vwMidia.asp?idGaleria=14\&idMidia=18812\&intMenuTipo=2> . Acesso em 8 out. 2008.

McDONALD, D. (2007) Visual Conversations Styles in Web Comunities. In: Proceedings of the $40^{\text {th }}$ Hawaii International Conference on System Sciences. Disponível em: <http:/ /csdl2.computer.org/comp/proceedings/hicss/2007/2755/00/27550076a.pdf>. Acesso em 5 out. 2008.

MONTARDO, S.P.; GOEDTEL, E. F.; ETCHEGARAY, M. S. Redes temáticas em fotologs: proposições iniciais para o estudo de caso sobre Síndrome de Down (SD). In: Revista Novas Tecnologias na Educação (Renote). Porto Alegre: UFRGS, Vol. 6, no. 1, Jul. 2008. Disponível em: <http://www.cinted.ufrgs.br/renote/ jul2008/artigos/4a_sandra.pdf.> Acesso em 9 out. 2008.

MONTARDO, S. P. ; PASSERINO, L. Espelhos quebrados no ciberespaço: implicações de redes temáticas em blogs na Análise de Redes Sociais (ARS). Trabalho aceito no GT Comunicação e Cibercultura, do $17^{\circ}$. Encontro da Associação Nacional de Programas de Pós-Graduação em Comunicação (Compós). São Paulo, UNIP, 2008. Disponível em <http:// www.compos.org.br>. Acesso em 10 out. 2008.

. Inclusão social via acessibilidade digital: proposta de inclusão digital para Pessoas com Necessidades Especiais (PNE). In: $e$ Compós.Edição8.Abr.2007.Disponívelem:<http:/ / www.compos.org.br/ecompos/adm/documentos/ ecompos08_abril2007_passerino_montardo.pdf $>$. Acesso em 10 out. 2008.

. Estudo dos blogs a partir da netnografia: possibilidades e limitações. In: Revista Novas Tecnologias na Educação (Renote). Porto Alegre: UFRGS, Vol. 4, no. 2, Dez. 2006. Disponível em: <http:// www.cinted.ufrgs.br/renote/dez2006/artigosrenote/25065.pdf>. Acesso em 10 out. 2008.

MOREIRA LEITE, M. Texto visual e texto verbal. In: FELDMAN-BIANCO, B.; MOREIRA LEITE, M. Desafios da imagem. Fotografia, iconografia e vídeo nas ciências sociais. Campinas, SP: Papirus, 1998.

PEREIRA SILVA, N. L.; DESSEN, M. A.Síndrome de Down: etiologia, caracterização e impacto na família. In: Revista Interação em Psicologia, 2002, 6 (2), p. 167-176.

RECUERO, R. Práticas de sociabilidade em sites de redes sociais: Interação e capital social nos comentários dos fotologs. In: $17^{\circ}$. Encontro da Associação Nacio- nal dos Programas de Pós-Graduação em Comunicação Social. Disponível em: <http:/ / www.compos.org.br>. Acesso em 10 out. 2008.

. Comunidades em Redes Sociais na Internet. Proposta de tipologia baseada no Fotolog.com. Tese de Doutorado. Programa de Pós-Graduação em Ciências da Comunicação e da Informação. Universidade Federal do Rio Grande do Sul. Porto Alegre, 2006.

Comunidades virtuais em redes sociais: uma proposta de estudo In: E-Compós, Brasilia, Compós, v.4, Dez 2005. (2005). Acesso em 5 out. 2008.

RIGONI, D. A vivência dos jovens nas comunidades virtuais: indicativo para ações pedagógicas. In: Associação Brasileira de Educação à Distância. Anais. 2006. Disponível em <http:/ / www.abed.org.br/seminario2006/pdf/tc017.pdf>. Acesso em 5 out. 2008.

RUTTER, J. SMITH, G. Etnographic Presence in a Nebulous Setting. In: HINE, C.(Org.).Virtual Methods. Issues in Social Research on the Internet. Oxford: Berg, 2005.

SPOSATI, A.A fluidez da inclusão/exclusão social. Ciência e Cultura, vol. 58, no. 4., São Paulo, Out/Dec. 2006.

WARSCHAUER, M. Tecnologia e Inclusão Social. A exclusão digital em debate. 